\title{
Mood disorders associated with Anti Epileptics
}

\author{
Supriya Chavan* and Kedar Prabhavalkar \\ Bhanuben Nanavati College of Pharmacy, India
}

Submission: April 30, 2018; Published: May 16, 2018

*Corresponding author: Supriya Chavan, Bhanuben Nanavati College of Pharmacy, Mumbai, India; Email: supriya_chavan1991@yahoo.in

\begin{abstract}
Mood disorder is not only the result of chronic stress or post-traumatic stress; Neurological disorder is also a leading source of it. This review represents a case study of an epileptic individual, suggesting realigning the focus of treatment more towards its psychiatric orientations. In adulthood epilepsy, it is necessary to maintain person's quality of life that is on antiepileptics. Antidepressants in combination with AED's should be preferred line of management to maintain the balance between psychiatric well-being and epilepsy.
\end{abstract}

Keywords: Mood disorder; Antiepileptics; Antidepressants; Preferred line of treatment

Abbreviations: AED: Anti Epileptic Drugs; EEG: Electro Encephalogram; CAM: Complementary and Alternative Medicine

\section{Introduction}

Epilepsy is one of the multifaceted neurological disorders with a peak incidence in childhood Approximately 50 million people currently live with epilepsy [1]. It is defined as having two or more unprovoked seizures. Seizures are the result of excessive discharges in a group of brain cells [2]. A "case study" which has briefly construed in this article at succeeding stages, emphases on epilepsy and associated psychiatric comorbidities; mood disorders are most common culprit of it [3]. Psychiatric disorders ranging from mild to severe, identified in $25 \%$ to $50 \%$ of patients with epilepsy [4] and it might instigated by any antiepileptic drugs (AED) [5]. Other factors influencing an expression of psychiatric complications such as person's individualities, severity of seizures and poly or monotherapy of AEDs, are often devastating [6]. An epileptic person most likely to face issues such as, difficulty in attention, inability to solve problem, aggressiveness, inferiority complex [4]. In the same way Anxiety, Depression misapprehension, discrimination and social stigma have surrounded epilepsy for centuries [3]. Despite the fact that AEDs exacerbate the already existing behavioural complications [7] they are still the mainstay of treatment in epilepsy [4].

\section{Case Study}

The patient is 25 years old female began to have symptoms of depression 8-12 months prior to case presentation. On presentation to the clinic for evaluation she reported that she had begun to experience memory disturbance and language difficulties since last 3 years before visiting clinic later developed social fear, inferiority, paranoia and aggressiveness.
Her family reported Prior history of viral meningitis at the age of seven, followed by an episode of epilepsy at the age of 21 which was initially considered as a partial seizures and no significant treatment was initiated till first six months. Later there was one unprovoked episode of generalized seizure followed by multiple partial seizures in forthcoming months. It was diagnosed as focal epilepsy with nonconclusive EEG studies, Brain MRI suggestive of old scar of temporal region. The patient primarily was on oxcarbazepine (300 mg twice a day for 4 years) which then substituted by Topiramet (50 mg twice a day) and sodium valproate XR (extended release) (250 $\mathrm{mg}$ twice a day) as an alternative treatment to initial treatment failure. Post having a close observation for about one year. The treatment was then switched to levetiracetam XR (650 mg once a day) and topiramet (50 mg twice a day), which was continued for 3 months due to side effects like lethargy, speech issues, weight loss. Eventually the treatment further changed to sodium valproate XR (250 $\mathrm{mg}$ twice a day) and levetiracetam (250 mg twice a day) which might be associated with the current symptoms.

\section{Clinical questions}

a) What is the clinical significance of depression in epilepsy?

b) How treatment failure does affects individual with epilepsy?

c) Is there any significance of adjuent antidepressants for betterment of patient's routine with minimal side effects? 
Results

Figure 1

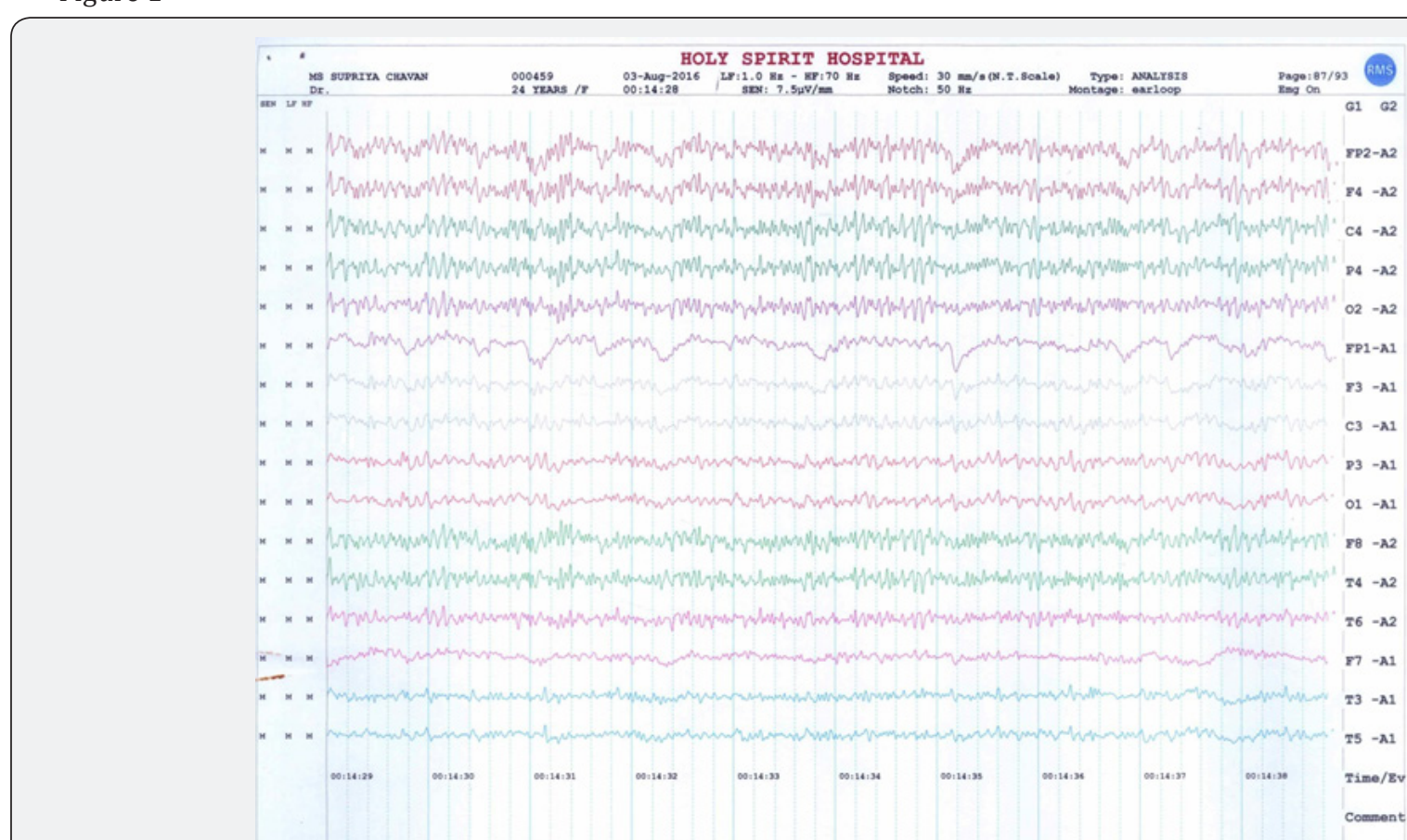

Figure 1: EEG done with 10-20 international system of electrodes placement background activity comprise of medium amplitude well modulated 9-10 Hz alpha activity, symmetrical synchronous, rhythemic and responsive to eye opening. Low amplitude, fast beta activity at $18-25 \mathrm{~Hz}$, recorded and best seen bifrontally. Occasionally theta activity intermixed.

\section{Discussion}

EEG demonstrates no major abnormalities. However, alterations involved in neural circuits considered as a primary suspect. In epilepsy due to abnormal functioning of brain electrical circuits have been attributed to ion channel mutations [7,8], therefore alterations in ion channel activity in relevant areas may also claimed in etiopathology of psychiatric disorders [9]. As mentioned in above case Oxcarbazepine and its metabolite 10-monohydroxy metabolite (MHD; in addition to its primary mechanism (i.e mechanism limiting the frequency of firing voltage dependent sodium channels) it might show clinically important effects on potassium channels [10-12]. $\mathrm{Na}^{+}$ and $\mathrm{K}^{+}$ion imbalance in brain regions caused by AED's might lead to possible comorbities in which dementia is highlighted: This might lead to confusion, affected speech etc. [13]. In above study it could be observed that, depression developed over a period of time possibly due to affected routine and performance of an individual especially in adults. The inferiority due to above symptoms in this group of adults might make them susceptible for psychological comorbidities higher than general population of adults. [14]. Many individuals with epilepsy may seek out the use of complementary and alternative medicine (CAM) to improve treatment outcome of traditional AED's. which includes drugs like Ginseng, Shankhapushpi, Bramhi etc. [15]. Although there have been no clear randomised studies that have evaluated the usefullness of CAM for epilepsy [16], unfortunately in many cases this treatment leads to seizure emergency [15]. Epilepsy disease and its symptoms are not universal and varises from individual [17], it frequently cited as one of condition in which combination therapies are more benifial over monotherapy [11]. In above case, two aspects of alternative tratments can be suggested one is CAM [15] and other is combination of AED's with mood stabilizers [18]. In above case invidual reperesented badly affected with mood instability might be because of possible side effect of frequent changes in therapy [19], after starting sertaline to manage depression, and changing AED Monotherapy to combination of Levetaraciatam and oxcarbazepine (doses as mentioned above). Improved management of epilepsy and its associated comorbidities.

\section{Conclusion}

It is important to screen disease condition carefully for which there is need for new and validated screening instruments, techniques and guidelines to help early detection of treatment of comorbid conditions. Investigational treatment includes AED's as well as mood stabilizers. Mood stabilizers help to reduce dose dependent comorbidities of AED's (18). Future advances in the investigation of the comorbidities of epilepsy will strengthen our understanding of epilepsy and could play an important part in stratification for genetic studies. Preliminary evidence suggests that some conditions, such as depression and migraine, negatively affect seizure outcome and quality of life. Further investigation is needed to explore these relations and the effects 
of targeted interventions which could be assess by counselling and psychotherapy in combination with AEDs might improve the state. In case of epilepsy and associated depression, side effects of AED's and affected cognition as mentioned in above case study, combination of glutamate NMDA modulators (levetiracetam) and mood stabilizers, as well as effective counselling of a patient will lead better management of a disease.

\section{References}

1. Megiddo I, Colson A, Chisholm D, Dua T, Nandi A (2016) Health and economic benefits of public financing of epilepsy treatment in India: An agent-based simulation model. Epilepsia 57(3): 464-474.

2. Liberalesso P, Silva I, Klagenberg K (2009) Incidence and Risk Factors for Seizures in Central Nervous System Infections in Childhood. J Epilepsy Clin Neurophysiology 15(2): 83-88.

3. Nadkarni S, Devinsky O (2005) Psychotropic Effects of Antiepileptic Drugs. Epilepsy Curr 5(5): 176-181.

4. La France WC, Kanner AM (2008) Psychiatric comorbidities in epilepsy. Int Rev Neurobiol 83: 347-83.

5. BA Lynch (2004) The synaptic vesicle protein SV2A is the binding site for the antiepileptic drug levetiracetam. Proc Natl Acad Sci USA 101(26): 9861-9866.

6. Scheuer ML, Pedley TA (1990) The evaluation and treatment of seizures. N Engl J Med 323(21): 1468-1474.

7. Gaitatzis A, Trimble MR, Sander JW (2004) The psychiatric comorbidity of epilepsy. Acta Neurologica Scand 110(4): 207-220.

8. Gur-Ozmen S, Mula M, Agrawal N, Cock HR, Lozsadi D, Oertzen TJ (2017) The effect of depression and side effects of antiepileptic drugs on injuries in patients with epilepsy. European Journal of Neurology 24(9): 1135-1139.

9. Ertem DH, Dirican AC, Aydın A, Baybas S, Sözmen V, et al. (2017) Exploring psychiatric comorbidities and their effects on quality of life in patients with temporal lobe epilepsy and juvenile myoclonic epilepsy. Psychiatry Clin Neurosci 71(4): 280-288.

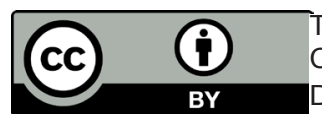

This work is licensed under Creative Commons Attribution 4.0 License DOI: 10.19080/PBSIJ.2018.09.555757
10. Mc Lean MJ, Schmutz M, Wamil AW, Olpe HR, Portet C, et al. (1994) Oxcarbazepine: mechanisms of action. Eplepsia 35(3): S5-9.

11. Mckee PW, Blacklaw J, Forrest G (1994) A double-blind, placebocontrolled interaction study between oxcarbazepine and carbamazepine, sodium valproate and phenytoin in epileptic patients. British Journal of clinical Pharmacology 37(1): 27-32.

12. Larkin JG, Mckee PW, Forrest G (1991) Lack of enzyme induction with oxcarbazepine (600 mg daily) in healthy subjects. British Journal of Clinical Pharmacology 31(1): 65-71.

13. Vitvitsky VM, Garg SK, Keep RF, Albin RL, Banerjee R (2013) $\mathrm{Na}^{+}$ and $\mathrm{K}^{+}$ion imbalances in Alzheimer's disease. Biochim Biophys Acta 1822(11): 1671-1678.

14. Keezer MR, Sisodiya M (2016) Comorbidities of epilepsy: current concepts and future perspectives. Lancet Neurol 15(1): 106-115.

15. E Mathew, J Muttappallymyalil, J Sreedharan (2013) Self-Reported Use of Complementary and Alternative Medicine among the Health Care Consumers at a Tertiary Care Center in Ajman, United Arab Emirates. Ann Med Health Sci Res 3(2): 215-219.

16. Templeman K, Robinson A (2015) Student identification of the need for complementary medicine education in Australian medical curricula: A constructivist grounded theory approach. Complement Ther Med 23(2):257-264.

17. Barbara CJ (2015) Consensus over Individualism: Validation of the ILAE Definition for Drug Resistant Epilepsy. Epilepsy Curr 15(4): 172173.

18. Cardamone L, Salzberg MR, O'Brien TJ, Jones NC (2013) Antidepressant therapy in epilepsy: can treating the comorbidities affect the underlying disorder? Br J Pharmacol 168(7): 1531-1554.

19. Madhukar HT, Ben TK (2017) Managing Depressive Disorders in Patients with Epilepsy. Psychiatry (Edgmont) 4(1): 26-34.

\section{Your next submission with Juniper Publishers} will reach you the below assets

- Quality Editorial service

- Swift Peer Review

- Reprints availability

- E-prints Service

- Manuscript Podcast for convenient understanding

- Global attainment for your research

- Manuscript accessibility in different formats

( Pdf, E-pub, Full Text, Audio)

- Unceasing customer service

Track the below URL for one-step submission https://juniperpublishers.com/online-submission.php 